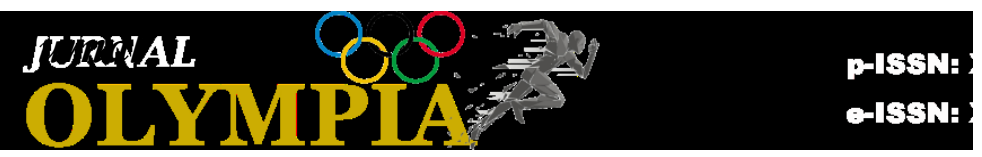

http://journal.binadarma.ac.id/index.php/olympia

\title{
Analisis Anxiety Atlet Futsal Saat Sebelum Bertanding Siswa Ekstrakulikuler SMPIT Thariq Bin Ziyad Boarding School Cikarang
}

\author{
Andini Dwi Intani ${ }^{1}$, Romi Mulyadi ${ }^{2}$
}

Universitas Islam 45 Bekasi $^{1}$, Universitas Islam 45 Bekasi², Indonesia

\begin{tabular}{l} 
Info Artikel \\
\hline Sejarah Artikel: \\
Diterima Februari 2020 \\
Disetujui Maret 2020 \\
Dipublikasikan \\
Mei 2020
\end{tabular}

$\overline{\text { Anxiety, Analisis, Futsal, }}$ Boarding School

\begin{abstract}
Abstrak
Penelitian ini bertujuan untuk mengetahui faktor-faktor penyebab anxiety dan upaya-upaya mengatasi anxiety menghadapi pertandingan pada atlet futsal. Metode penelitian yang digunakan untuk penelitian ini adalah ex post facto. Populasi dan sampel yang digunakan dalam penelitian ini adalah atlet futsal SMPIT Thariq Bin Ziyad Boarding School, dengan menggunakan teknik purposive sampling. Berdasarkan hasil analisis data menunjukan bahwa tingkat anxiety atlet futsal SMPIT Thariq Bin Ziyad Boarding School. Cukup baik tidak ada satu orangpun yang mengalami anxiety berlebihan. Hanya 50\% (6 orang) yang mengalami anxiety sedang 33\% (4 orang) mengalami anxiety rendah dan $17 \%$ ( 2 orang) yang mengalami anxiety tinggi. Artinya tingkat anxiety atlet tidak ada yang sangat tinggi pada saat sebelum pertandingan dimulai.
\end{abstract}

\begin{abstract}
This study aims to determine the factors that cause anxiety and efforts to overcome anxiety in the face of competition in futsal athletes. The research method used for this research is ex post facto. The population and sample used in this study were futsal athletes at Thariq Bin Ziyad Boarding School SMPIT, using purposive sampling technique. Based on the results of data analysis shows that the anxiety level of futsal athletes at SMPIT Thariq Bin Ziyad Boarding School. It's good enough that no one experiences excessive anxiety. Only 50\% (6 people) had moderate anxiety 33\% (4 people) had low anxiety and $17 \%$ (2 people) had high anxiety. This means that the athlete's anxiety level is not very high before the game starts.
\end{abstract}

E-mail: intaniandini@gmail.com romimulyadi8@gmail.com
ISSN 2656-5994 (online) ISSN 2656-5986 (cetak) 


\section{PENDAHULUAN}

Berbagai

cabang

olahraga

dipertandingkan dalam turnamen antar wilayah sampai antar sekolah. Salah satu yang dipertandingkan adalah olahraga Futsal. Futsal adalah permainan yang dimainkan oleh dua tim, yang masing-masing beranggotakan lima orang. Tujuannya adalah memasukkan bola ke gawang lawan. Selain lima pemain utama, setiap regu juga diizinkan memiliki pemain cadangan. Tidak seperti permainan bola dalam ruangan lainnya, lapangan futsal dibatasi garis, bukan net atau papan Justinus Lhaksana (2012:5).

Olahraga adalah skenario gerak tubuh terstruktur dan peraturan yang dibungkus dengan ritme dengan tujuan menciptakan kondisi manusia dari fisik, mental atau spiritual yang sehat (Hidayat, 2019). Prestasi olahraga sangat ditentukan dari penampilan diri pemain dalam suatu kompetisi. Penampilan puncak seorang pemain $80 \%$ dipengaruhi oleh aspek mental dan hanya 20\% oleh aspek yang lainnya, sehingga aspek mental harus diberikan pembinaan dengan baik (Gunarsa, 1989).

Proses pembinaan hanya memperhatikan pembinaan fisik dan keterampilannya semata dengan mengesampingkan atau kurang memberikan perhatian khusus terhadap hal-hal yang menyangkut aspek psikis, sehingga mengakibatkan kurang optimalnya penampilan pemain dalam mengikuti kompetisi atau pertandingan. Hal tersebut dikarenakan prestasi olahraga tidak dapat hanya bergantung pada keterampilan teknis olahraga dan kesehatan fisik yang dimiliki oleh atlet yang bersangkuatan, tetapi juga tergantung pada keadaan keadaan psikiologis dan mental yang dimiliki atlet.

Faktor psikis merupakan kunci dari keberhasilan dan kesuksesan seorang atlet atau sebuah tim. Atlet harus memiliki psikis yang stabil dan dapat mengalahkan segala tekanan non-teknis, seperti halnya atmosfer pertandingan, penonton atau suporter dan beban yang diberikan pada pengurus. Hal ini ditujukan untuk meraih prestasi setinggitingginya dan semaksimal mungkin. Tingkat pencapaian prestasi puncak sangat ditentukan oleh kematangan dan ketangguhan mental atlet dalam mengatasi berbagai kesulitan dalam sebuah pertandingan. Banyak atlet yang tidak sukses mewujudkan kemampuan optimalnya hanya karena rasa cemas dan takut gagal yang berlebihan.

Kenyataannya ketika turnamen bergulir, sering nampak seorang atlet atau tim yang sudah mempunyai kemampuan fisik yang baik, teknik yang sempurna, dan sudah dibekali berbagai taktik, tetapi tidak dapat mewujudkannya dengan baik di arena pertandingan atau perlombaan, dan akhirnya mengalami kekalahan. Kecemasan pada atlet tidak hanya merugikan diri sendiri, namun juga mengakibatkan permainan dalam tim terganggu.

Kecemasan merupakan reaksi situasional terhadap berbagai rangsang stres (Straub, 1987). Weinberg (1989) mengatakan 
kecemasan sebagai keadaan emosi yang negatif yang disertai perasaan tegang, cemas, dan ketakutan yang dihubungkan dengan aktivasi atau arousal pada tubuh. Berdasarkan jenisjenisnya, anxiety dibagi menjadi dua macam yaitu state anxiety dan trait anxiety.

Trait anxiety adalah rasa cemas yang merupakan sifat pribadi/bawaan (sifat pencemas). Menurut Singgih D. Gunarsa (2008: 74) trait anxiety adalah suatu predisposisi untuk mempersepsikan situasi lingkungan yang mengancam dirinya. Seorang olahragawan pada dasarnya memiliki trait anxiety maka manifestai kecemasannya akan selalu berlebihan dan mendominasi aspek psikisnya. Hal ini merupakan kendala yang serius bagi olahragawan tersebut untuk dapat berpenampilan baik.

Menurut Apta Mylsidayu (2017: 54) Anxiety yang berlebihan pada olahragawan dapat menimbulkan gangguan pada perasaan yang kurang menyenangkan, sehingga kondisi fisik olahragawan berada dalam keadaan kurang/tidak seimbang, adanya gangguan anxiety yang kompleks pada olahragawan dapat membuat keadan menjadi lebih buruk karena fokus perharian olahragwan menjadi terpecah-pecah pada saat yang bersamaan. Akibatnya olahragwan terpaksa memfokuskan energi psikofisiknya untuk mengembalikan kembali kondisinya keadaan yang seimbang dan konsentrasi olahragawan untuk menghadapi lawan menjadi berkurang.

Ketegangan dan kecemasan saling terkait dan selalu muncul dalam kegiatan olahraga. Ketegangan yang dialami oleh setiap individu akan berbeda beda, hal ini disebabkan oleh perbedaan pengalaman, kepekaan, dan cara menaggapi situasi (Hale, 2016). Dampak dari ketegangan terhadap penampilan gerak pada olahragawan antara lain menimbulkan kecemasan, emosi, ketegangan pada otot, kelentukan, dan koordinasi (Baker, Côté, \& Hawes, 2000). Kecemasan memiliki dua komponen yaitu terdiri dari kecemasan kognitif dan (cognitive anxiety) yang ditandai dengan rasa gelisah dan ketakutan akan sesuatu yang terjadi, sedangkan yang ke dua adalah kecemasan somatik (somatic anxiety). Khawatir adalah cara bicara diri yang negatif yang sering mencegah pikiran fokus pada masalah yang dihadapi sehingga menghalangi seseorang menyelesaikan masalah tersebut secara optimal. Sedangkan sisi emosional kecemasan adalah gejala psikologik yang menyertai seperti berkeringat, detak jantung meningkat, dam tekanan darah menjadi meninggi. Jadi, dapat disimpulkan bahwa komponen kecemasan terdiri atas dua komponen yakni kecemasan kognitif (pikiran) dan somatik (gejala psikologik).

\section{METODOLOGI PENELITIAN}

Metode penelitian yang digunakan dalam penelitian ini adalah metode ex post facto. Menurut Mia Kusumawati (2017:106) ex post facto adalah penelitian yang dilakukan setelah kejadian, atau treatrmentnya memang sudah dilakukan dan sudah berlangsung. Penelitian ex post facto secara metodis 
merupakan penelitian eksperimen yang juga menguji hipotesis tetapi tidak memberikan perlakuan-perlakuan tertentu karena suatu sebab kurang etis untuk memberikan perlakuan atau memberikan manipulasi.

\section{Populasi dan Sempel}

Populasi merupakan subyek penelitian. Menurut Sugiyono (2012: 117) populasi adalah wilayah genelarisasi yang terdiri atas obyek atau subjek yang mempunyai kulaitas dan karakteristik tertentu yang diterapkan oleh peneliti untuk dipelajari dan kemudian ditarik kesimpulannya. adapun populasi dalam penelitian ini adalah atlet futsal Smpit Thariq Bin Ziyad yang berjumlah 24 orang.

Menurut Suharsimi Arikunto (2014: 174) bahwa: "sempel adalah bagian dari populasi (sebagian atau wakil populasi yang diteliti)". Dalam penelitian ini penulis menggunakan teknik penentuan sempel pertimbangan tertentu.

Purposive sampling dilakukan dengan cara mengambil subjek bukan diataskan strata, rondoom atau daerah tetapi didasarkan atas adanya tujuan tertentu. Teknik ini biasanya dilakukan karena bebrapa petimbangan, misalnya alasan keterbatasan waktu, tenaga dan dana sehinnga tidak mengambil sampel yang besar dan jauh.

Berdasarkan pendapat diatas maka sempel dalam penelitian ini ada bebrapa persyaratan antara lain: (1) atlet tim inti (2) atlet tim cadangan. Sesuai dengan kriteria diatas maka sempel dalam penelitian ini hanya berjumlah 12 orang atlet dalam satu tim.

\section{Instrumen Penelitian}

Untuk menghasilkan data dalam penelitian yang dilakukan, digunakan alat pengumpulan data (instrumen penelitian). Instrumen penelitian yang digunakan dalam penelitian ini adalah Angket

Angket dalam penelitian ini terdiri komponen atau variable yang dijabarkan melalui sub komponen, indikator-indikator dan pernyataan, butir-butir pernyataan itu merupakan gambaran tentang tingkat status sebelum pertandingan, selama pertandingan dan sesudah pertandingan. Bentuk angket yang digunakan dalam penelitian ini adalah angket tertutup.

\section{Prosedur Analisis Data}

Untuk memperoleh suatu kesimpulan masalah yang diteliti, maka analis data merupakan suatu langkah yang penting dalam penelitian. Data yang sudah terkumpul akan tidak berarti apa-apa apabila tidak diolah, karena itu perlu adanya analisis data tersebut.

Pengguanan analisis dapat dilaksakan dengan dua jenis analisa yaitu analisis statistik dan analisis non statistik. Dalam penelitian seorang dapat memakai salah satu analisis tersebut. Karena data yang terkumpul harus berupa angka-angka, maka penulis menggunakan analisis statistik.

Dengan analisa statistik maka obyektivitas dari hasil penelitian akan lebih terjamin. Analisa statistik dapat memberikan efesiensi dan efektivitas kerja karena dapat membuat data agar lebih ringkas bentuknya. 
Metode analisa yang dapat digunakan adalah analisa deskriptif dengan perhitungan rumus :

$$
\mathrm{DP}=\mathrm{n} / \mathrm{N} \times 100 \%
$$

Keterangan:

DP $=$ Deskriftip Presentase

$\mathrm{n}$ = Skor emperik (skor yang diperoleh)

$\mathrm{N}=$ Skor ideal / jumlah total nilai responden

(Suharsimi Arikunto 2010: 186).

\section{HASIL DAN PEMBAHASAN}

Penelitian ini membahas hubungan anxiety dikaitkan dengan kemampuan permainan futsal pada atlet SMPIT Thariq Bin Ziyad Boarding School Cikarang Utara Kabupaten Bekasi, hasil tes dan pengukuran menunjukan hasil sebagai berikut :

Tabel 1. Destripsi data

\begin{tabular}{|c|c|c|c|c|c|}
\hline & N & Jumlah & $\begin{array}{c}\text { Rata- } \\
\text { Rata }\end{array}$ & Maks & Min \\
\hline Anxiety & 12 & 34,84 & 2,9 & 3,69 & 2,34 \\
\hline
\end{tabular}

Anxiety yang dilihat dalam penelitian ini terdiri dari dua aspek, yaitu state anxiety dan trait anxiety. Anxiety dilihat pada saat akan bertanding permainan olahraga futsal. Dari 12 atlet SMPIT Thariq Bin Ziyad Boarding School Cikarang yang dilakukan pengambilan data melalui kuisioner. Hasil dirangkum dalam tabel dibawah ini.

Tabel 2. Tingkat Anxiety atlet

SMPIT Thariq Bin Ziyad boarding School Cikarang

\begin{tabular}{|c|c|c|c|}
\hline $\begin{array}{c}\text { Rantang } \\
\text { Nilai }\end{array}$ & Interpretasi & $\mathrm{F}$ & Prosentase \\
\hline $\begin{array}{c}\text { Sangat } \\
\text { Rendah }\end{array}$ & $1.00-1.79$ & 0 & $0 \%$ \\
\hline
\end{tabular}

\begin{tabular}{|c|c|c|c|}
\hline $\begin{array}{c}\text { Rantang } \\
\text { Nilai }\end{array}$ & Interpretasi & F & Prosentase \\
\hline Rendah & $1.80-2.59$ & 4 & $33 \%$ \\
\hline Sedang & $2.60-3.39$ & 6 & $50 \%$ \\
\hline Tinggi & $3.40-4.19$ & 2 & $17 \%$ \\
\hline $\begin{array}{c}\text { Sangat } \\
\text { Tinggi }\end{array}$ & $4.20-5.00$ & 0 & $0 \%$ \\
\hline
\end{tabular}

Dari tabel diatas dapat dilihat bahwa tingkat anxiety atlet futsal SMPIT Thariq Bin Ziyad Boarding School Cikarang, pada saat mengikuti turnamen Sacitra Cup tidak cukup baik namun tidak satu orangpun yang mengalami anxiety berlebihan. Hanya 17\% (2 orang) yang mengalami anxiety tinggi, 50\% (6 orang) mengalami anxiety sedang dan 33\% (4 orang) yang anxietynya rendah.

\section{Diskusi dan Penemuan}

Dari analisis data ditemukan beberapa hal pada atlet futsal SMPIT Thariq Bin Ziyad, diantaranya tingkat anxiety atlet futsal SMPIT Thariq Bin Ziyad pada saat mengikuti pertandingan tidak ada yang mengalami anxiety sangat tinggi. Atlet futsal SMPIT Thariq Bin Ziyad lumayan cukup baik tidak ada kecemasan yang berlebihan/sangat tinggi pada saat mengikuti pertandingan dengan tidak adanya atlet yang mengalami anxiety sangat tinggi maka diharapkan kemampuan dalam bertanding bertambah baik. Namun jika dilihat dari hasil pertandingan Sacitra Cup tingkat Kabupaten Bekasi. Belum bisa memberikan hasil yang maksimal.

Berdasarkan hasil penelitian ternyata tidak ada atlet yang mengalami anxiety sangat tinggi bahkan rata rata atlet mengalami anxiety 
yang sedang, oleh karna itu dugaan pertama penulis tentang anxiety atlet yang berlebihan ternyata salah, hanya saja jam terbang dan jadwal latihan atlet yang hanya seminngu 2 kali dan minimnya latihan tanding yang dilakukan diluar sekolah yang membuat atlet kurang maksimal pada saat mengikuti lomba pada turnamen sacitra cup 2019.

Temuan ini menurut penulis, dengan tidak adanya atlet yang sangat mengalami anxiety tinggi namun hasil pertandingan belum memperlihatkan hasil yang maksimal. Menurut penulis atlet futsal SMPIT Thariq Bin Ziyad belum memiliki kemapuan yang maksimal terutama pada kondisi fisik mereka yang mempengaruhi permainan. Oleh karena itu perlu perhatian bagi pelatih futsal SMPIT Thariq Bin Ziyad dimasa yang akan datang agar memberikan program latihan yang sesuai dengan sering mengadakan latihan bertanding dengan sekolah-sekolah yang memiliki prestasi lebih baik di tempat mereka agar atlet futsal SMPIT Thariq Bin Ziyad terbiasa bermain diluar sekolah.

\section{SIMPULAN}

Berdasarkan hasil penelitian dan pembahasan, maka peneliti dapat menyimpulkan bahwa hasil analisis data menunjukan hasil analisis data terdapat 33\% (4 orang) yang memiliki anxiety rendah 50\% (6 orang) memiliki anxiety sedang dan 17\% (2 orang) memiliki anxiety tinggi, hasil itu mennjukan tingkat anxiety atlet SMPIT Thariq Bin Ziyad dalam kategori sedang, artinya atlet tidak memiliki kecemasan yang berlebihan, namun masih harus diperbaiki kemampuan teknik bermainnya dan meingkatkan kondisi fisiknya.

\section{DAFTAR PUSTAKA}

Benny, B. 2010. Latihan Taktik BEYB Bermain Futsal Modern. Kota Bekasi: Penerbit Cakrawala Cendekia.

Baker, J., Côté, J., \& Hawes, R. (2000). The relationship between coaching behaviours and sport anxiety in athletes. Journal of Science and Medicine in Sport. https://doi.org/10.1016/S14402440(00)80073-0

Hale, B. D. (2016). Competitive Anxiety in Sport. The Sport Psychologist. https://doi.org/10.1123/tsp.5.3.292

Hidayat, A. (2019). Effect of agility ladder exercises on agility of participants extracurricular futsal at Bina Darma University. Journal of Physics: Conference Series, Volume 140(Issue 5, 2019 (055001-055110)). https://doi.org/10.1088/17426596/1402/5/055003

Justinus Lhaksana, dan Ishak H. Pordasi. 2009. Inspirasi dan Spirit Futsal. Jakarta : Raih Asa Sukses.

Kusumawati, Mia. 2017. Penelitian Pendidikan Penjas. Bekasi kota: Penerbit percetakan samadiru.

Lhaksana, Justinus. 2012. Taktik Dan Dasar Strategi Futsal Modern. Depok: Be Champoion.

Mylsidayu, Apta. 2017. Mental Training.Bekasi Kota: Penerbit Cakrawala Cendikia.

Nana Sudjana, Ibrahim. 2004. Penelitian dan Penelitian Pendidikan : Penerbit Sinar Buku Algensindo. 
Suharsimi, Arikunto. 2014. Prosedur Penelitian. Jakarta: Penerbit PT. Reanika cipta.

Sugiono. 2012. MetodePenelitian Pendidikan. Bandung: Penerbit Alpabeta.

Singgih D. Gunarsa. 2008. Psikologi Olahraga Prestasi. Jakarta : PT BP Gunung Mulia.

Weinbergt, Robet S. 2003. Foundations Of Sport And Exercise Psycology. USA: Human Kinetic. 